\title{
PREDIKSI TINGKAT KELULUSAN NILAI MAHASISWA TERHADAP MATAKULIAH WEB PROGRAMMING MENGGUNKAN METODE NEURAL NETWORK
}

\author{
Mochammad Abdul Azis; Agung Fazriansyah ${ }^{2}$ \\ 1Program Studi Ilmu Komputer \\ STMIK Nusa Mandiri \\ www.nusamandiri.ac.id \\ mochammad.mmz@nusamandiri.ac.id; agungfaz1305@bsi.ac.id
}

\begin{abstract}
The application of information technology in the world of education can also produce abundant data about student data and the value of learning produced. Like the leading course scores which greatly affect the number of GPA and graduation because if one of the leading courses such as Web Programming gets a D grade then the student cannot register the Final Project or Thesis. One way is to classify student value data to find out what is the most crucial pre-eminent courses from the first semester, using the Neural Network classification method that has advantages in large data and provides accurate predictions of passing student grades in order to get precise accuracy to classify graduation of excellent subjects in the Information Systems study program. From the results of this study obtained an accuracy value of 95.67\% and a ROC graph with an AUC (Area Under Curve) value of 0.939 .
\end{abstract}

Keywords: Graduation, Neural Network, Student Grades, Web Programming.

Intisari-Penerapan teknologi informasi dalam dunia pendidikan juga dapat menghasilkan data yang berlimpah mengenai data mahasiswa dan nilai pembelajaran yang dihasilkan. Seperti nilai matakuliah unggulan tersebut yang sangat mempengaruhi jumlah ipk dan kelulusan karna jika salah satu matakuliah unggulan seperti Web Programming tersebut mendapatkan nilai D maka mahasiswa tersebut tidak dapat melakukan pendaftaran Tugas akhir atau Skripsi. Salah satu caranya adalah dengan melakukan klasifikasi data nilai mahasiswa untuk mengetahui nilai matakuliah unggulan apa saja yang paling krusial dari semester pertama, dengan menggunakan metode klasifikasi Neural Network yang memiliki kelebihan dalam data yang besar dan memberikan prediksi kelulusan nilai mahasiswa yang akurat agar mendapatkan akurasi yang tepat untuk melakukan klasifikasi kelulusan terhadap matakuliah unggulan pada program studi Sistem Informasi. Dari hasil penelitin ini mendapatkan nilai accuracy sebesar $95.67 \%$ dan grafik ROC dengan nilai AUC (Area Under Curve) sebesar 0,939 .

Kata Kunci: Kelulusan, Neural Network, Nilai Mahasiswa, Web Programming.

\section{PENDAHULUAN}

Ketua program studi sistem informasi perlu mengerahkan seluruh sumber daya yang dimiliki untuk membantu mahasiswa menyelesaikan pendidikan mereka dengan prestasi akademik yang baik dan meminimalisir tingkat ketidak lulusan mahasiswa, Tentunya dalam perguruan tinggi kelulusan mahasiswa penting terutama dalam penilaian akreditasi perguruan tinggi, Sedangkan dalam perguruan tinggi memiliki data mahasiswa yang bisa digunakan untuk keperluaan pengambilan keputusan untuk pengembangan sistem belajar dalam perguruan tinggi.

Salah satunya caranya adalah dengan melakukan klasifikasi data nilai mahasiswa untuk mengetahui nilai matakuliah unggulan apa saja yang paling krusial dari semester pertama.

Pada teknik data mining dan model data driven yang terkenal yang sering digunakan pada penelitian-penelitian yang ada telah banyak dilakukan dengan beberapa teknik yaitu DT, SVM, NB dan NN. Dari beberapa model yang ada kami menggunakan model neural network yang dikarenakan data yang kita uji coba menggunakan data besar yang hanya dapat dilakukan oleh model neural network tersebut.

Neural Network lebih flesksibel yaitu tidak ada batasan apriori yang dikenakan bila dibandingkan dengan pemodelan statistic klasik (Ridwansyah \& Purwaningsih, 2018), sehingga Neural Network cenderung memberikan prediksi yang akurat (Moro, Laureano, \& Cortez, 2011). Neural network memiliki kelebihan pada prediksi non linear, memiliki performa yang lebih baik dan memiliki kemampuan dengan tingkat kesalahan 
rendah (Moro, Cortez, \& Rita, 2014) \& (Muzakkir, Syukur, \& Dewi, 2014).

Penelitian sebelumnya ini dalam memprediksi kelulusan mahasiswa yang mempengaruhi proses akreditasi dengan menggunakan algoritma klasifikasi data mining $K$ Nearest Neighbor dengan mengklaster data $k=1$, $k=2, k=3, k=4$, dan $k=5$. Hasil yang diperoleh dengan cluster data $k=5$ accuracy adalah $85,15 \%$ dan nilai AUC adalah 0.888 adalah akurasi paling tinggi(Rohman, 2015). Prediksi kelulusan mahasiswa juga telah dilakukan dengan mengambil data nilai Web Programming menggunakan algoritma neural network dengan jumlah data 870 dengan hasil yaitu semakin banyak data training maka semakin akurat hasil yang didapat.

Berdasarkan latar belakang yang telah disebutkan diatas, Bagaimana penelitian ini dengan menerapkan algoritma neural network untuk mengetahui mahasiswa yang lulus pada matakuliah web programming yang menjadi matakuliah unggulan pada program studi sistem informasi? dan dagaimana penelitian ini dengan menerapkan algoritma neural network untuk mengatahui akurasi mahasiswa kelulusan matakuliah Web Programming dan tujuan penelitian ini mengklasifkasi kelulusan mahasiswa di salah satu perguruan tinggi swasta yang ada di Jakarta Indonesia terhadap matakuliah unggulan pada program studi Sistem Informasi dan agar mendaparkan akurasi yang tepat untuk melakukan klasifikasi kelulusan terhadap matakuliah unggulan pada program studi Sistem Informasi dengan menggunakan metode klasifikasi Neural Network.

\section{BAHAN DAN METODE}

Dalam penelitian ini akan memanfaatkan data mining untuk proses mengklasifikasi data nilai mahasiswa dengan menggunakan algoritma Neural Network.

Proses klasifikasi didasarkan pada empat komponen (Gorunescu, 2011):

dari nim, kode matakuliah, absensi, nilai tugas, nilai uts, nilai uas, nilai akhir, dan 1 variabel tujuan yaitu Lulus atau Tidak Lulus yang dapat dilihat pada table 1 :
1. Class : Variabel dependen yang berupa kategorikal yang mempersentasikan label yang terdapat pada objek

2. Predictor : Variabel independen yang direpresentasikan oleh karakteristik (atribut) data. Contohnya :kode matakuliah, nim.

3. Training dataset : Satu set data yang berisi nilai dari kedua komponen diatas yang digunakan untuk menentukan kelas yang cocok berdasarkan predictor.

4. Testing dataset : Berisi data baru yang akan diklasifikasikan oleh model yang telah dibuat dan akurasi klasifikasi dievaluasi.

Adapun kerangka pemikiran yang dilakukan adalah :

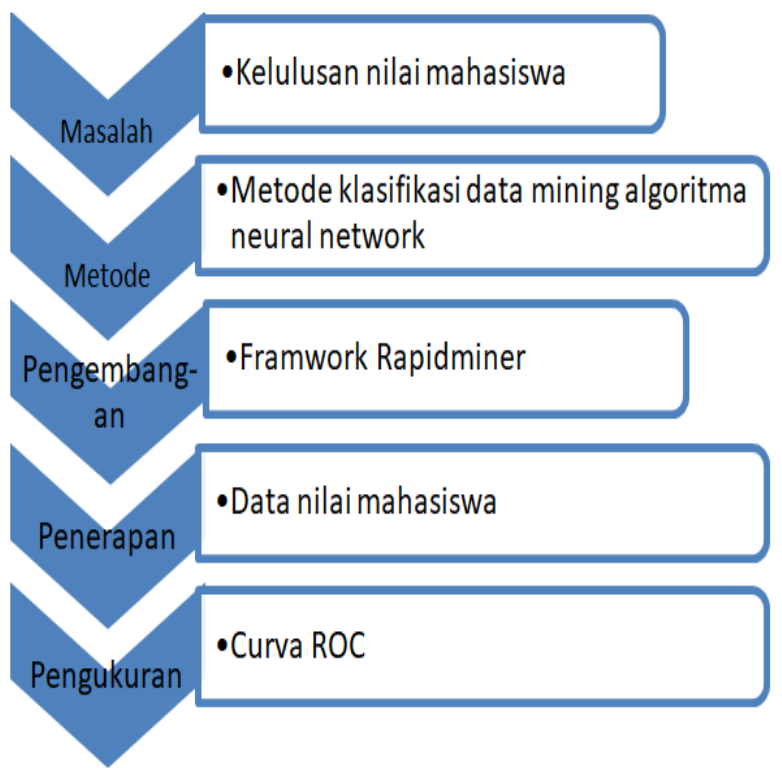

Sumber: (Azis \& Hermawan, 2019)

Gambar 1. Kerangka Pemikiran

Dalam penelitian ini digunakan data primer yang di peroleh dari salah satu perguruan tinggi swasta yang ada di Jakarta di Indonesia. Pengumpulan data yang digunakan adalah data primer yang didapatkan dari database dari salah satu perguruan tinggi swasta yang ada di Jakarta di Indonesia dengan jumlah data sebanyak 870 record, dengan variable sebagai penentu terdiri

Tabel 1. Data Nilai Web Programming

\begin{tabular}{cccccccc}
\hline Nim & Kd_Mtk & Absen & Nilai_Tugas & Nilai_Uts & Nilai_Uas & Nilai_Akhir & Status \\
\hline 11131949 & 726 & 8 & 100 & 60 & 60 & 59,6 \\
\hline 11132245 & 726 & 9 & 100 & 78 & 73 & 68,2 \\
\hline
\end{tabular}




\begin{tabular}{|c|c|c|c|c|c|c|c|}
\hline $\mathrm{Nim}$ & Kd_Mtk & Absen & Nilai_Tugas & Nilai_Uts & Nilai_Uas & Nilai_Akhir & Status \\
\hline 11132298 & 726 & 8 & 80 & 50 & 50 & 49,1 & 0 \\
\hline 11132299 & 726 & 5 & 80 & 60 & 50 & 51 & 0 \\
\hline 11132359 & 726 & 9 & 100 & 50 & 40 & 51,3 & 0 \\
\hline 11132365 & 726 & 8 & 80 & 45 & 45 & 46,35 & 0 \\
\hline 11132487 & 726 & 9 & 100 & 45 & 45 & 51,55 & 0 \\
\hline 11132555 & 726 & 23 & 100 & 50 & 50 & 57,1 & 1 \\
\hline 11132573 & 726 & 23 & 80 & 50 & 50 & 52,1 & 0 \\
\hline 11132600 & 726 & 12 & 100 & 100 & 100 & 82,4 & 1 \\
\hline 11132688 & 726 & 8 & 85 & 50 & 45 & 48,85 & 0 \\
\hline 11132738 & 726 & 17 & 95 & 62 & 58 & 60,05 & 1 \\
\hline 12120605 & 726 & 5 & 100 & 75 & 75 & 67,25 & 1 \\
\hline 12122419 & 726 & 6 & 100 & 50 & 50 & 53,7 & 0 \\
\hline 12122431 & 726 & 13 & 100 & 50 & 40 & 52,1 & 0 \\
\hline 12123209 & 726 & 10 & 100 & 70 & 70 & 65,5 & 1 \\
\hline 12123370 & 726 & 11 & 100 & 60 & 60 & 60,2 & 1 \\
\hline 12123499 & 726 & 8 & 100 & 50 & 50 & 54,1 & 0 \\
\hline 12123636 & 726 & 10 & 100 & 58 & 57 & 58,6 & 1 \\
\hline 12123638 & 726 & 10 & 100 & 50 & 50 & 54,5 & 0 \\
\hline 12123687 & 726 & 4 & 100 & 50 & 55 & 54,8 & 0 \\
\hline 12123976 & 726 & 8 & 100 & 50 & 40 & 51,1 & 0 \\
\hline 12124001 & 726 & 9 & 100 & 70 & 70 & 65,3 & 1 \\
\hline 12125031 & 726 & 9 & 100 & 65 & 65 & 62,55 & 1 \\
\hline 12125055 & 726 & 8 & 100 & 65 & 65 & 62,35 & 1 \\
\hline 12125213 & 726 & 3 & 100 & 40 & 40 & 47,6 & 0 \\
\hline 12125309 & 726 & 3 & 100 & 70 & 75 & 65,6 & 1 \\
\hline 12125981 & 726 & 10 & 90 & 50 & 50 & 52 & 0 \\
\hline 12126202 & 726 & 5 & 100 & 50 & 45 & 52 & 0 \\
\hline 12126368 & 726 & 12 & 100 & 70 & 65 & 64,4 & 1 \\
\hline 12126414 & 726 & 9 & 100 & 30 & 20 & 40,3 & 0 \\
\hline
\end{tabular}

Sumber: (Azis \& Hermawan, 2019)

\section{HASIL DAN PEMBAHASAN}

Setelah melakukan hasil eksperimen yang kami lakukan pada data mahasiwa yang didapat dari salah satu perguruan tinggi swasta yang ada di Jakarta Indonesia. Untuk diolah pada aplikasi rapidminer dan jika sudah masuk dihalaman awal lalu masukan data ke read excel lalu import data set 870 record. Ganti Status menjadi label lalu finish.

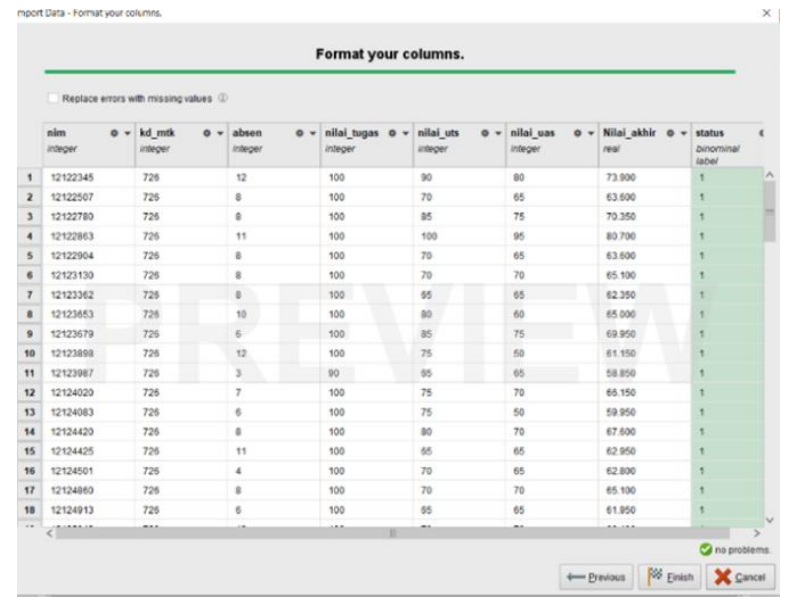

Sumber: (Azis \& Hermawan, 2019)

Gambar 2. Import Data 
Setelah data sudah di import ke read excel, replace missing values dan cross validation lalu sambungkan tiap proses.

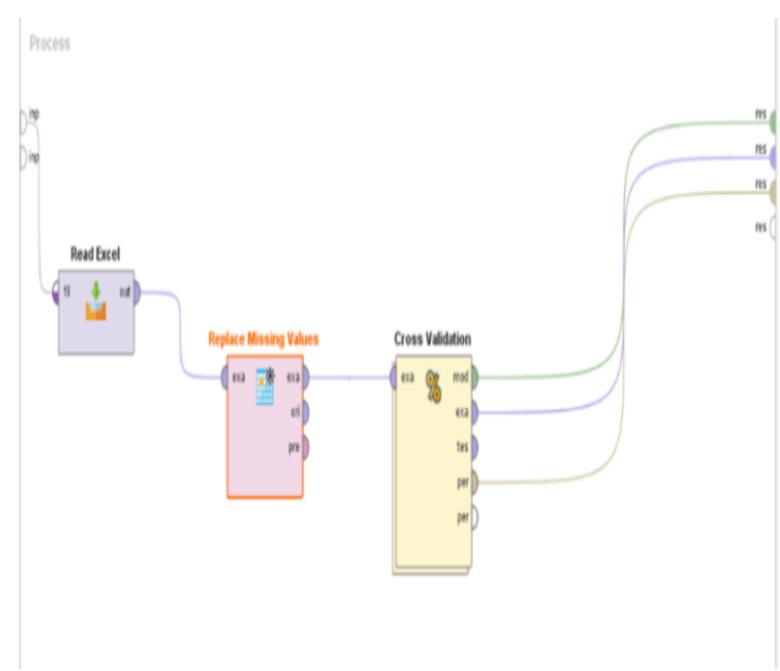

Sumber: (Azis \& Hermawan, 2019)

Gambar 3. Proses Awal

Setelah itu klik cross validation dan masukan algoritma Neural Network dalam proses Training, Apllay Model dan Performance kedalam proses testing.

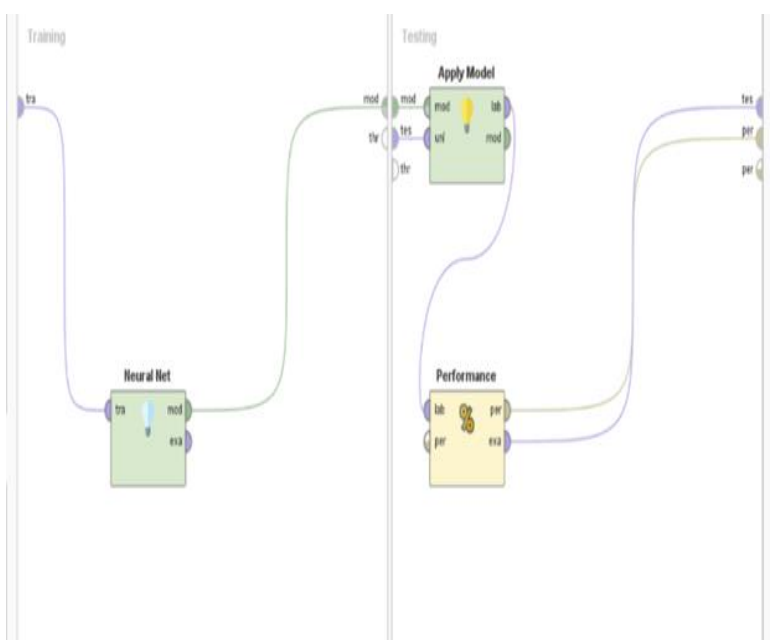

Sumber: (Azis \& Hermawan, 2019)

Gambar 4. Training dan Testing
Penerapan model neural network berdasarkan nilai akurasi dalam penelitian kami maka terbentuk arsitektur neural network seperti pada Gambar2.

$$
\text { Input Hidden } 1 \quad \text { Output }
$$

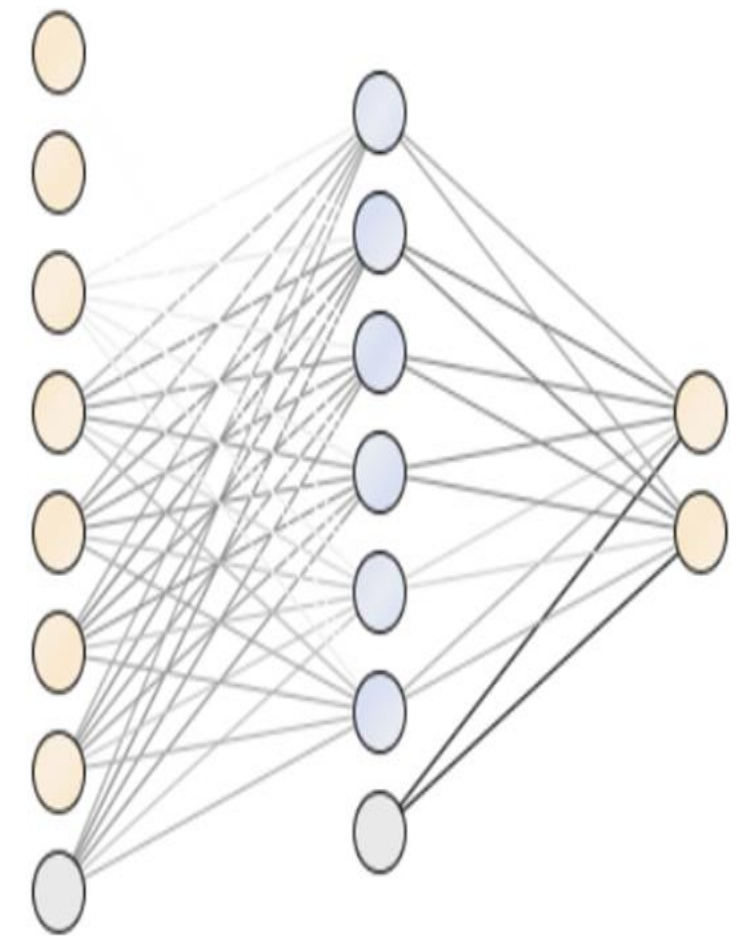

Sumber: (Azis \& Hermawan, 2019)

Gambar 5. Arsitektur Neural Network

Pada desain model algoritma neural network diatas dilakukan proses training model dengan memberikan:

1. Hidden Layer Size : 7

2. Training Cycles : 200

3. Learning Rate : 0.01

4. Momentum : 0.9

Berdasarkan hasil dari uji coba dengan menggunakan algoritma neural network maka hasil dari hidden layar size yang didapat yaitu :

Tabel 2. Hidden Layer Size Atribut Metode Neural Network

\begin{tabular}{|c|c|c|c|c|c|c|c|c|}
\hline Sigmoid & $\mathrm{Nim}$ & Kd Mtk & Absen & Nilai Tugas & Nilai UTS & Nilai UAS & Nilai Akhir & Bias \\
\hline Node 1 & 0.006 & -0.039 & 0.659 & 3.975 & 3.373 & 3.551 & 3.258 & -3.430 \\
\hline Node 2 & -0.048 & -0.002 & 0.788 & 4.177 & 4.382 & 4.651 & 4.296 & -4.538 \\
\hline Node 3 & -0.033 & -0.036 & 0.736 & 3.745 & 3.999 & 4.240 & 3.876 & -4.127 \\
\hline Node 4 & -0.024 & 0.028 & 0.741 & 3.634 & 3.942 & 4.163 & 3.777 & -4.015 \\
\hline Node 5 & 0.123 & 0.017 & 0.576 & 1.578 & 2.297 & 2.286 & 2.038 & -2.254 \\
\hline
\end{tabular}




\begin{tabular}{lllllllll}
\hline Sigmoid & Nim & Kd Mtk & Absen & Nilai Tugas & Nilai UTS & Nilai UAS & Nilai Akhir & Bias \\
\hline Node 6 & 0.030 & 0.034 & 0.626 & 2.598 & 3.090 & 3.190 & 2.899 & -3.091 \\
\hline \multicolumn{2}{l}{ Sumber: (Azis \& Hermawan, 2019) }
\end{tabular}

Proses training seperti itu mendapatkan nilai accuracy sebesar 95.67\% dan grafik ROC dengan nilai AUC (Area Under Curve) sebesar 0,939 dengan diagnosa hasilnya Excellent classification lihat Gambar 6.

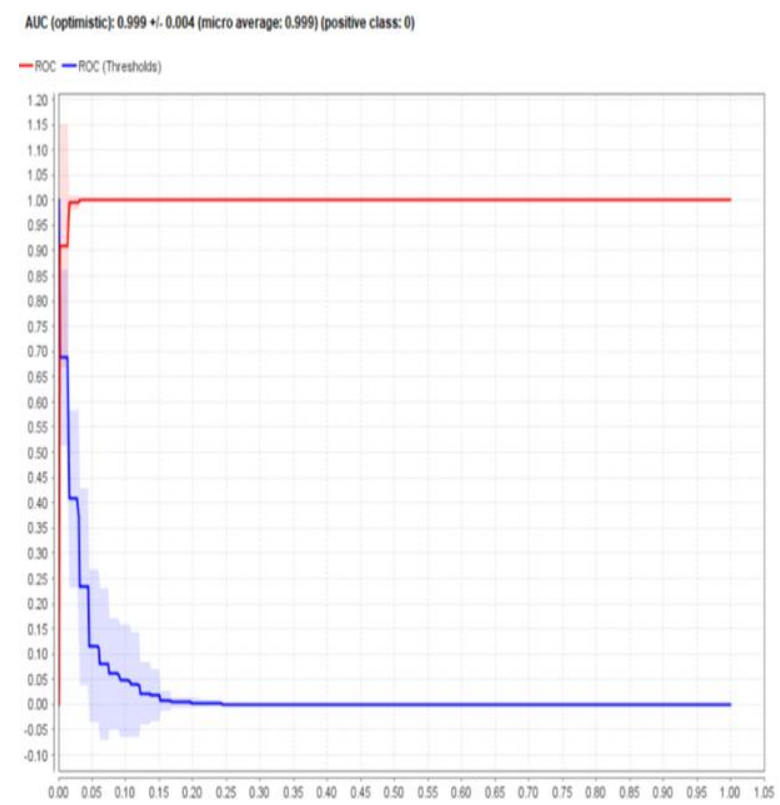

Sumber: (Azis \& Hermawan, 2019)

Gambar 6. nilai AUC dalam Grafik ROC algoritma neural network

Pengujian model setelah melakukan dengan penerapan neural network dalam menentukan tingkat keakurasian maka confusion matrix yang didapat baik model neural network itu sendiri berdasarkan 870 data yang diolah yaitu :

Tabel 3. Nilai Akurasi dengan NN

\begin{tabular}{llcl}
\hline \multicolumn{4}{c}{ Accuracy: 98,85\% } \\
\hline & true 1 & True 0 & $\begin{array}{l}\text { class } \\
\text { precision }\end{array}$ \\
\hline pred. 1 & 656 & 4 & $99.39 \%$ \\
\hline pred. 0 & 6 & 205 & $97.16 \%$ \\
\hline Class recall & $99.09 \%$ & $98.09 \%$ & \\
\hline \multicolumn{5}{l}{ Sumber: (Azis \& Hermawan, 2019) }
\end{tabular}

$$
\begin{aligned}
\text { Akurasi } & =\frac{(\mathrm{TN}+\mathrm{TP})}{(\mathrm{TN}+\mathrm{FN}+\mathrm{TP}+\mathrm{FP})} \\
& =\frac{(656+205)}{(656+6+205+4)} \\
& =0,9885
\end{aligned}
$$

Berdasarkan Tabel 2 dapat diklasifikasikan sebagai berikut :

True positive $(t p)=205$ record

False Negative $(f n)=425$ record

True Negative $(t n)=656$ record

False Negative $(f p)=4$ record

Dari hasil klasifikasi menunjukkan bahwa, tingkat akurasi dengan menggunakan algoritma neural network adalah sebesar 98,85\%.

\section{KESIMPULAN}

Hasil penelitian ini menyimpulkan bahwa data kelulusan terhadap matakuliah unggulan dapat diprediksi dengan menggunakan model algoritma Neural Network, dengan hasil akurasi : 98.85\% +/-1.71\%(Micro average :98.85\%) paling tinggi dibandingkan dengan model algoritma lainnya, sehingga dengan prediksi ini dapat membantu dalam dalam kelulusan matakuliah unggulan pada Prodi Sistem Informasi.

\section{REFERENSI}

Azis, M. A., \& Hermawan, A. (2019). Laporan Akhir Penelitian Mandiri. Jakarta.

Gorunescu, F. (2011). Data Mining: Concepts, Models and Techniques (Intelligent Systems Reference Library).

Moro, S., Cortez, P., \& Rita, P. (2014). A data-driven approach to predict the success of bank telemarketing. Decision Support Systems, 62, 22-31.

https://doi.org/10.1016/j.dss.2014.03.001

Moro, S., Laureano, R. M. S., \& Cortez, P. (2011). Using Data Mining for Bank Direct Marketing: An application of the CRISP-DM methodology. 25th European Simulation and Modelling Conference-ESM'2011, (Figure 1), 117-121.

Muzakkir, I., Syukur, A., \& Dewi, I. N. (2014). PENINGKATAN AKURASI ALGORITMA BACKPROPAGATION DENGAN SELEKSI FITUR PARTICLE SWARM OPTIMIZATION DALAM PREDIKSI PELANGGAN TELEKOMUNIKASI YANG HILANG. Pseudocode, 1(1), 1-10. 
https://doi.org/10.33369/PSEUDOCODE.1.1.

$1-10$

Ridwansyah, R., \& Purwaningsih, E. (2018).

PARTICLE SWARM OPTIMIZATION UNTUK

MENINGKATKAN AKURASI PREDIKSI

PEMASARAN BANK. Jurnal Pilar Nusa

Mandiri, 14(1), 83-88.

https://doi.org/10.33480/PILAR.V14I1.94

Rohman, A. (2015). Model Algoritma K-Nearest Neighbor (K-Nn) Untuk Prediksi Kelulusan

Mahasiswa. Neo Teknika, 1(1).

https://doi.org/10.1017/CB0978110741532

4.004 